\title{
Bacteriological survey of tuberculous lymphadenitis in South-east England: 1973-80
}

\author{
JOHN GRANGE, CHRISTOPHER COLLINS, AND MALCOLM YATES \\ From the Department of Microbiology, Cardiothoracic Institute, and the Public Health Laboratory Service \\ Regional Centre for Tuberculosis Bacteriology, Dulwich Hospital, London, UK
}

SUMmaRY During the eight years 1973-80 the Public Health Laboratory Service Regional Centre for Tuberculosis Bacteriology received cultures of mycobacteria from 2339 patients with tuberculous lymphadenitis. Of these, 2272 were $M$ tuberculosis (2207 human and 65 bovine strains) and 67 were other mycobacterial species, usually $M$ avium and its intracellulare variant. Disease due to the human strains of $M$ tuberculosis occurred most often in young women of Asian ethnic origin. Many bovine strains isolated from Asian patients differ from the classical bovine type in being sensitive to pyrazinamide: the origin of these strains, whether from other people or from cattle, is unknown. Lymphadenitis due to bovine strains tended to occur in an older age group than the human strains and probably include relatively more cases of reactivation diseases. Infection caused by the other mycobacterial species occurred mainly in young children of European origin. Tuberculosis, therefore, remains an important cause of lymphadenopathy in Britain.

\footnotetext{
'Tis called the evil;

A most miraculous work in this good king Which often, since my here-remain in England, I've seen him do. How he solicits heaven Himself best knows; but strangely-visited people All swol'n and ulcerous, pitiful to the eye, The mere despair of surgery, he cures, Hanging a golden stamp about their necks Put on with holy prayers; and 'tis spoken, To the succeeding royalty he leaves The healing benediction.
}

These words, from Shakespeare's Macbeth, refer to one of the most fascinating diseases of history-namely, scrofula or the King's Evil. The latter name originated from the widespread belief that a touch from the reigning monarch had curative properties. This custom was allegedly introduced in the fifth century by Clovis I of France after he had dreamed that he had received this divine gift. The monarch, after due prayer and fasting, would touch the afflicted patients while saying "The king touches thee and God heals thee," and would then hang a golden "touchpiece" around the sufferer's neck. The practice died out in England after Queen Anne failed to cure Samuel Johnson, but it persisted in France well into the nineteenth century. ${ }^{1}$
The origin of the term scrofula is unknown. It is thought to be derived from the Latin scrofa, a breeding sow, although the reason for such a derivation remains a mystery. Early writers used it in reference to a "strumous" swelling in the neck. Later scrofula and the expression King's Evil covered a variety of swellings and ulcerations, many of which were probably non-tuberculous in origin. ${ }^{2}$ Villemin, ${ }^{3}$ however, in a brilliant series of studies on the transmissible agent of tuberculosis two decades before Robert Koch cultured the bacillus firmly re-established the synonymity of scrofula and tuberculosis. Nowadays the term is applied to superficial tuberculous lymphadenopathy, particularly when it affects the cervical region.

Although of historical interest, and despite the decline in the incidence of tuberculosis in Britain during the last century, tuberculous lymphadenopathy is not rare. In this study we review the bacteriologically confirmed cases referred to the Public Health Laboratory Service Regional Centre for Tuberculosis Bacteriology, Dulwich, during the years 1973-80 inclusive.

Materials and methods

The PHLS Regional Centre for Tuberculosis 
Bacteriology at Dulwich receives positive cultures of Mycobacterium tuberculosis and other species of mycobacteria from the great majority of hospitals in London and South-east England. All isolates are identified by the methods described by Collins and Lyne. ${ }^{4}$ Cultures are examined macroscopically and microscopically. All acid-fast bacilli are screened by cultural tests (pigment production, growth at $25^{\circ} \mathrm{C}$, and growth in the presence of $p$-nitrobenzoic acid) that separate $M$ tuberculosis from other species. Sensitivity tests to appropriate antituberculous drugs are begun at the same time. If at any time is is suspected that the organism is not $M$ tuberculosis, full identification procedures are begun.

Organisms identified as $M$ tuberculosis are subdivided into classical and Asian variants of the human type and classical and Afro-Asian variants of the bovine type by the methods of Yates and Collins. ${ }^{5}$

Details of the age, sex, ethnic origin, and anatomical site of the lesions were supplied by the referring laboratory or physician. Cases of lymph node tuberculosis diagnosed by other methods-for example, histology-are not included in this study.

\section{Results}

During the eight years 1973-80 inclusive, 2339 cultures of mycobacteria isolated from human lymph nodes were submitted to the PHLS Regional Centre for Tuberculosis Bacteriology. Of these, 2272 were strains of $M$ tuberculosis, including 2207 identified as the human and 65 as the bovine type. Sixty-seven isolates belonged to other mycobacterial species.

The annual number of isolates of the human type of $M$ tuberculosis was fairly constant, and most isolates were from patients of Asian ethnic origin (table 1). The most often affected nodes were the cervical and axillary nodes (table 2). In both Asian and European patients the disease was most frequent in the third decade of life, while among the Europeans there was also a high incidence in older age groups, particularly in the eighth decade (fig). In both ethnic groups the disease was more frequent among women; the male to female ratio was $1: 1.4$ among Asians and $1: 2 \cdot 1$ among Europeans.

The 65 strains of the bovine type of $M$ tuberculosis were isolated from cervical nodes, except for one

Table 1 Annual number of isolations of the human type of $M$ tuberculosis according to the ethnic origin of the patients

\begin{tabular}{|c|c|c|c|c|c|c|c|c|c|c|}
\hline \multirow{2}{*}{$\begin{array}{l}\text { Ethnic origin } \\
\text { of patient }\end{array}$} & \multicolumn{8}{|l|}{ Year } & \multirow[b]{2}{*}{ Total } & \multirow[b]{2}{*}{$\%$} \\
\hline & 1973 & 1974 & 1975 & 1976 & 1977 & 1978 & 1979 & 1980 & & \\
\hline Asian & 156 & 166 & 202 & 169 & 195 & 241 & 183 & 178 & 1490 & $67 \cdot 6$ \\
\hline European & 63 & 95 & 93 & 83 & 75 & 62 & 69 & 70 & 610 & $27 \cdot 6$ \\
\hline Other & 14 & 10 & 4 & 8 & 13 & 17 & 14 & 27 & 107 & $4 \cdot 8$ \\
\hline Total & 233 & 271 & 299 & 260 & 283 & 320 & 266 & 275 & 2207 & \\
\hline
\end{tabular}

Table 2 Site of origin of the human type of $M$ tuberculosis

\begin{tabular}{|c|c|c|c|c|c|c|c|c|c|c|}
\hline \multirow[b]{2}{*}{ Site of disease } & \multicolumn{8}{|l|}{ Year } & \multirow[b]{2}{*}{ Total } & \multirow[b]{2}{*}{$\%$} \\
\hline & 1973 & 1974 & 1975 & 1976 & 1977 & 1978 & 1979 & 1980 & & \\
\hline $\begin{array}{l}\text { Neck, axilla } \\
\text { Thorax } \\
\text { Abdomen } \\
\text { Unspecified }\end{array}$ & $\begin{array}{r}157 \\
17 \\
5 \\
54\end{array}$ & $\begin{array}{r}179 \\
9 \\
2 \\
81\end{array}$ & $\begin{array}{r}223 \\
9 \\
2 \\
65\end{array}$ & $\begin{array}{r}212 \\
4 \\
4 \\
40\end{array}$ & $\begin{array}{r}234 \\
5 \\
8 \\
36\end{array}$ & $\begin{array}{r}271 \\
7 \\
21 \\
21\end{array}$ & $\begin{array}{r}215 \\
10 \\
29 \\
12\end{array}$ & $\begin{array}{r}240 \\
5 \\
23 \\
7\end{array}$ & $\begin{array}{r}1731 \\
66 \\
94 \\
316\end{array}$ & $\begin{array}{r}78 \cdot 4 \\
3 \cdot 0 \\
4 \cdot 3 \\
14 \cdot 3\end{array}$ \\
\hline Total & 233 & 271 & 299 & 260 & 283 & 320 & 266 & 275 & 2207 & \\
\hline
\end{tabular}

Table 3 Annual number of isolations of the bovine type of $M$ tuberculosis according to the ethnic origin of the patients

\begin{tabular}{|c|c|c|c|c|c|c|c|c|c|}
\hline \multirow{2}{*}{$\begin{array}{l}\text { Ethnic origin } \\
\text { of patient }\end{array}$} & \multicolumn{8}{|l|}{ Year } & \multirow[b]{2}{*}{ Total } \\
\hline & 1973 & 1974 & 1975 & 1976 & 1977 & 1978 & 1979 & 1980 & \\
\hline Asian & 2 & 4 & 2 & 3 & 0 & 6 & 12 & 0 & 29 \\
\hline African & 1 & 0 & 0 & 0 & 2 & 5 & 1 & 1 & 10 \\
\hline European & 2 & 3 & 2 & 2 & 3 & 6 & 6 & 2 & 26 \\
\hline Total & 5 & 7 & 4 & 5 & 5 & 17 & 19 & 3 & 65 \\
\hline
\end{tabular}


strain from an inguinal node (table 3 ). The Asian patients were aged 18-50, the Africans 24-46, and, with the exception of a 3-year-old child, the Europeans 49-84. During 1978-80 inclusive, all 14 isolates from Europeans were resistant to pyrazinamide while 10 of 18 isolates from Asian patients differed from the typical bovine types in being sensitive to this agent.

The 67 isolates of mycobacteria other than $M$ tuberculosis were from cervical nodes except for one isolate from an inguinal node of an 82-year-old European patient. Most isolates were M avium, including the intracellulare variant (table 4). Six isolates were from Asians, all children under 5; 61 isolates were from Europeans, 44 from children under 10, six from children aged 10-16, three from adults, and eight from patients of unknown age.

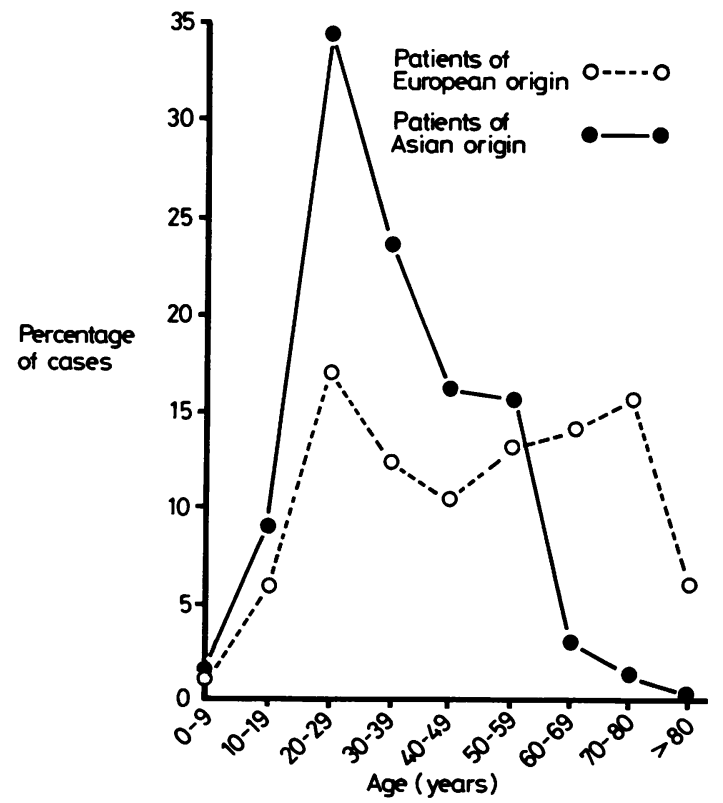

Distribution of cases of lymphadenopathy due to human strains of Mycobacterium tuberculosis according to age.

\section{Discussion}

It has been firmly established that in Britain the incidence of tuberculosis is relatively much higher among people of Asian ethnic origin than among those of European origin. ${ }^{-a}$ It has also been established that the incidence of extrapulmonary manifestations of tuberculosis is relatively commoner among the Asian group, and that the most often encountered form of such extrapulmonary tuberculosis is lymphadenitis, particularly of the cervical region. ${ }^{10-13}$

The incidence of bacteriologically proved cases of tuberculous lymphadenitis is much lower than the total incidence of the disease. Positive cultures are obtained only in $30-50 \%$ of all such cases. ${ }^{814}$ This may be due to a low number of organisms in the lesions-much of the swelling being due to hypersensitivity reactions. In attempting to culture the organisms it is important to process whole tissue rather than pus, in which the bacilli are killed by free fatty acids. It is also possible that, owing to variations in the metabolic properties of the different species, their isolation rate does not accurately reflect their true incidence in infections. The culturability of other mycobacterial species in lymph nodes is not known and probably varies from centre to centre according to the techniques used. In one study ${ }^{15}$ such bacteria appeared to be much more difficult to obtain in culture than $M$ tuberculosis.

The results of this survey are in agreement with the observations of Campbell and Dyson ${ }^{11}$ on 108 cases-namely, that the disease was commoner among persons of Asian origin and that it occurred more often among women and young people (mean age 35). These authors also noted, from their own and other published studies, that Europeans were more likely than Asians to be infected with bovine strains of $M$ tuberculosis or with other mycobacterial species. Nevertheless, human strains of $M$ tuberculosis were by far the commonest cause of infection in both ethnic groups.

The notion that tuberculous cervical lymphadenopathy is usually caused by the bovine

Table $4 \cdot$ Annual number of isolations of mycobacteria of species other than $M$ tuberculosis

\begin{tabular}{|c|c|c|c|c|c|c|c|c|c|}
\hline \multirow[b]{2}{*}{ Isolate } & \multicolumn{8}{|l|}{ Year } & \multirow[b]{2}{*}{ Total } \\
\hline & 1973 & 1974 & 1975 & 1976 & 1977 & 1978 & 1979 & 1980 & \\
\hline$M$ avium/intracellulare & 7 & 13 & 4 & 10 & 4 & 4 & 5 & 9 & 56 \\
\hline$M$ scrofulaceum & 1 & 1 & 1 & 0 & 1 & 0 & 0 & 0 & 4 \\
\hline$M$ kansasii & 0 & $\mathbf{0}$ & 0 & 1 & 0 & 0 & 0 & 0 & 1 \\
\hline$M$ chelonei & 2 & 0 & 1 & 0 & 0 & 0 & 1 & 1 & 5 \\
\hline$M$ xenopi & $\mathbf{0}$ & 1 & 0 & $\mathbf{0}$ & $\mathbf{0}$ & $\mathbf{0}$ & o & 0 & 1 \\
\hline Total & 10 & 15 & 6 & 11 & 5 & 4 & 6 & 10 & 67 \\
\hline
\end{tabular}


type of $M$ tuberculosis is a fallacy that has, unfortunately, been promulgated in several well-known textbooks. Even though this organism is relatively commoner in lymphatic tuberculosis than in other forms of the disease it has never been the major cause. ${ }^{16}$ In 1910 in the USA bovine strains were isolated from $11 \%$ of 1042 cases of all types of tuberculosis and from $35 \%$ of 119 cases of "glandular" tuberculosis. ${ }^{17}$ In 1937 Griffith found that bovine strains were responsible for half the cases of tuberculous cervical lymphadenopathy but that most cases due to this type occurred in children aged under 5 years. ${ }^{18}$

In this study infections due to bovine strains in Europeans were, with one exception, in those over the age of 49 and are probably due to reactivation of old primary lesions. In the case of human strains, however, there were two distinct peaks of incidence, one occurring among young adults. This suggests that primary infections are occurring.

Not only were bovine strains of $M$ tuberculosis relatively less frequent among Asian patients, but many of the isolates differed from classical bovine strains in being sensitive to pyrazinamide. Such variants have been termed Afro-Asian bovine strains. ${ }^{5}$ There is, however, no evidence that this variant is derived from cattle or any other animal. The use of the designation "bovine" for this strain is due entirely to its cultural similarity to classical bovine strains and carries no epidemiological significance. It should be noted, however, that even classical bovine strains isolated from man are not all due to infection from cattle; there is evidence also of man-to-man spread. ${ }^{19}$

The other mycobacterial species isolated from lymph nodes all differ from $M$ tuberculosis in that they are rarely, if ever, transmitted from man to man. They are essentially environmental saprophytes, and the incidence and distribution of opportunistic infections in man is independent of disease due to the obligate pathogen $M$ tuberculosis..$^{13}$ Therefore the incidence of such infections in the different ethnic groups should reflect the relative numbers of people in these groups in the given area. The reason for the preponderance of such infections in young children is unknown. It may have an immunological basis or it may simply be due to the propensity of children to insert parts of the contaminated environment into their mouths.

At present, there is no satisfactory immunological, bacteriological, or epidemiological explanation for the high incidence of tuberculous lymphdenitis among individuals of Asian origin. In 1797 Hufeland wrote that "scrofula is a much beclouded subject" and to this day the pathogenesis of this form of tuberculosis is poorly understood. Miller and
Cashman $^{21}$ considered that most cases occurring in childhood represented primary infections, and although $20 \%$ of patients had radiological evidence of pulmonary tuberculosis it was considered that these represented separate primary infections. Other workers have considered that this form of tuberculosis is just one facet of a generalised disease and is secondary to a focus of infection elesewhere, even though this may be very small. ${ }^{22}{ }^{23}$ Although classically tuberculous cervical adenitis affected the tonsillar nodes, it is now more usual to find infection in the supraclavicular nodes, probably as a result of lymphatic spread from an intrathoracic lesion.

Probably tuberculous lymphadenopathy comprises three fairly distinct entities of differing pathogenesis.

(1) Involvement of tonsillar nodes for young children as a result of drinking milk contaminated with bovine strains of $M$ tuberculosis.

(2) Involvement of cervical nodes for young children (or, rarely, other nodes and other age groups) by "environmental" species of mycobacteria.

(3) Involvement of any group of lymph nodes, but most often supraclavicular nodes, of older children and adults by human and, less often, bovine strains of $M$ tuberculosis. This type is apparently further divisible into primary and secondary types.

The first of these has been virtually eradicated by veterinary health measures and by the pasteurisation of milk. The second form may be expected to persist at a low but constant incidence irrespective of tuberculosis control measures. The third form, which is now far the commonest type, is. like all other forms of the disease, potentially preventable by tuberculosis control measures. Although commoner among Asians, it is an important cause of lymphadenitis among patients of European origin, especially in the second and third decade of life.

In conclusion, tuberculous lymphadenopathy is not just a historical curiosity, it is a prevalent modern-day cause of lymph node enlargement and should be seriously considered in the differential diagnosis of such a presenting feature.

\section{References}

${ }^{1}$ Crawford R. The king's evil. Oxford: Clarendon Press, 1911

${ }^{2}$ Wiseman R. A treatise on the king's evill. Eight chirurgical treatises. 3rd ed. London: Tooke and Meredith, 1696.

${ }^{3}$ Villemin JA. Etudes expérimentales et cliniques sur tuberculose. Paris; Bailliere et Fils, 1868: 181.

${ }^{4}$ Collins CH, Lyne PM. Microbiological methods. 4th ed (rev). London: Butterworth, 1979.

${ }^{5}$ Yates MD, Collins $\mathrm{CH}$. Identification of tubercle bacilli. Ann Microbiol (Paris) 1979; 130B: 13-9. 
${ }^{6}$ British Thoracic and Tuberculosis Association. A tuberculosis survey in England and Wales 1971; the influence of immigration and country of birth upon notification. Tubercle 1973; 54: 249-60.

${ }^{7}$ British Thoracic Association. Tuberculosis among immigrants in Britain. $\mathrm{Br}$ Med J 1978; i: 1038-40.

${ }^{8}$ Medical Research Council Tuberculosis and Chest Disease Unit. National survey of tuberculosis notifications in England and Wales 1978-9. Br Med J 1980; 281: 895-8.

${ }^{9}$ Collins $\mathrm{CH}$. Tuberculosis in Europeans and Asians. Commun Dis Rep 1975: No 45.

${ }^{10}$ Collins $\mathrm{CH}$, Yates MD. Isolation of mycobacteria from lymph nodes. Commun Dis Rep 1978; No 77/14.

${ }^{11}$ Campbell IA, Dyson AJ. Lymph node tuberculosis: a comparison of various methods of treatment. Tubercle 1977; 58: 171-9.

${ }^{12}$ Grange JM, Aber VR, Allen BW et al. Comparison of strains of Mycobacterium tuberculosis from British, Ugandan and Asian immigrant patients: a study in bacteriophage typing, susceptibility to hydrogen peroxide and sensitivity to thiophen-2-carbonic acid hydrazide. Tubercle 1977; 58: 207-15.

${ }^{13}$ Grange JM. The changing tubercle. Br J Hosp Med 1979; 22: $540-8$.
${ }^{14}$ Hooper AA. Tuberculous peripheral lymphadenitis. $\mathrm{Br} J$ Surg 1972; 59: 353-9.

${ }^{15}$ Schuit KE, Powell DA. Mycobacterial lymphadenitis in childhood. Am J Dis Child 1975; 132: 675-7.

${ }^{16}$ Wilmot TJ, James EF, Reilly LV. Tuberculous cervical adenitis. Lancet 1957; ii: 1184-7.

${ }^{17}$ Park WH, Krumweide C. The relative importance of the bovine and human types of tubercle bacilli in the different forms of human tuberculosis. J Med Res 1910; 23: 205-18.

${ }^{18} \mathrm{Griffith}$ AS. Bovine tuberculosis in man. Tubercle 1937; 18: $529-43$.

${ }^{19}$ Collins $\mathrm{CH}$, Yates MD, Grange JM. A study of bovine strains of Mycobacterium tuberculosis isolated from humans in South East England 1977-1979. Tubercle 1981: 62: 113-6.

$\approx$ Burke RM. An historical chronology of tuberculosis. 2nd ed. Springfield, Illinois: Charles C Thomas, 1955.

${ }^{21}$ Miller FJW, Cashman JM. Origin of peripheral tuberculous lymphadenitis in childhood. Lancet 1958; i: 286-9.

${ }^{22}$ Kent DC. Tuberculous lymphadenitis: not a localized disease. Am J Med Sci 1967; 254: 866-74.

${ }^{23}$ Newcombe J. Tuberculous glands in the neck. Br J Hosp Med 1979; 22: 553-5. 